\title{
The role of non-formal education in combating the HIV epidemic in the Philippines and Taiwan
}

\author{
Donald E. Morisky $\cdot$ Shu-Yu Lyu $\cdot$ Lianne A. Urada
}

Published online: 23 February 2010

(C) The Author(s) 2010. This article is published with open access at Springerlink.com

\begin{abstract}
The Philippines is experiencing a low but slowly growing prevalence of HIV, with a UN estimate of 6,000-11,000 cases out of a population of 91 million, and a $150 \%$ increase in new cases in 2008 compared to previous years. Earlier education programmes employed non-formal educational training techniques in the southern Philippines to target high-risk groups such as female sex workers and their establishment managers; the effort was expanded to target males in the community. In comparison, as of 2009, Taiwan has an estimated 40,000 cases of HIV/AIDS in a population of 23 million. It experienced a major increase in HIV infection among injecting drug users, from 77 newly reported cases in 2003 to 2,381 such cases in 2007. This article compares and contrasts the response to the epidemic in each country, describing non-formal educational programmes targeted and tailored to specific high-risk populations.
\end{abstract}

Keywords Philippines · Taiwan · HIV prevention · Non-formal education

\section{Introduction}

The rate of HIV infection continues to rise in several regions of the world, despite declining incidence rates in other countries. Therefore, measures to prevent its spread remain an

D. E. Morisky

School of Public Health, University of California, Los Angeles (UCLA), 650 Charles E. Young Drive South, Los Angeles, CA 90095-1772, USA

e-mail: dmorisky@ucla.edu

S.-Y. Lyu ( $\square)$

School of Public Health, Taipei Medical University, $250 \mathrm{Wu}$-Hsing Street, Taipei 11031, Taiwan, ROC

e-mail: sylyu@tmu.edu.tw

\section{A. Urada}

Department of Social Welfare, UCLA School of Public Affairs,

3250 Public Policy Bldg., Los Angeles, CA 90095-1656, USA

e-mail: urada@spa.ucla.edu 
urgent global priority. India, for example, is now considered the epicenter of the epidemic and has committed $70 \%$ of its HIV spending to prevention (Claeson and Alexander 2008).

Behavioural changes may prevent the spread of HIV in developing countries (Hearst et al. 1995), but a continuing challenge is to accurately measure and influence behavioural change. Few national data are available that measure how behavioural changes reduce the risk of HIV infection (Parkhurst 2008). Furthermore, process data such as the number of clients served or the number of condoms distributed are not very helpful measures (Davis et al. 2000). Better predictors of HIV prevention are consistent condom use versus "ever using a condom" and the number of concurrent partners an individual has versus their number of lifetime partners (Parkhurst 2008).

Culture and gender relations may also influence the acceptance of protective health measures even more than the physical characteristics of the prevention tool (Gollub 2008). Therefore, assessing structural factors is especially important when targeting hard-to-reach populations (Mantell et al. 2008).

UNESCO (1997) defines the term non-formal education as follows:

Any organized and sustained educational activities that do not correspond exactly to the definition of formal education. Non-formal education may therefore take place both within and outside educational institutions, and cater to persons of all ages. Depending on country contexts, it may cover educational programmes to impart adult literacy, basic education for out-of-school children, life-skills, work-skills, and general culture. Non-formal education programmes do not necessarily follow the "ladder" system, and may have differing durations, and may or may not confer certification of the learning achieved. (p. 47)

Some studies report that non-formal education programmes have mixed results (Vermund et al. 2009; Ellis 1995; Evans 1981). Critics of non-formal education say its effectiveness is too often assumed without proper evaluation, and that untested causal assumptions are frequently made about education and societal change (Benavot 2002). However, nonformal education serves as an alternative for populations that do not have readily available and accessible educational options (UNESCO 2006).

Globally, non-formal educators have addressed sexually transmitted infections (STI), especially in settings with limited resources (Latkin et al. 2009; Shah et al. 2007; Akani and Erhabor 2006). For example, in a randomly controlled HIV prevention trial, researchers observed improvements in service delivery, including referrals for HIV testing and provision of condoms, when non-formal care providers received enhanced training in HIV case management (Shah et al. 2007). Peer education, anti-AIDS clubs, drama, art, youth dialogues, music, and comic books are some examples of non-formal education. Non-formal educational activities were a key determinant in the tremendous decline in HIV prevalence in Uganda, where the Ministry of Education and Sports introduced national-level prevention campaigns in 1986 (Jacob et al. 2006). These activities included media messages targeting youth and school theatrical performances that depicted real-life scenarios facing youth. Plays were presented in over 8,500 primary schools nationwide, also reaching a large proportion of out-of-school youth. Non-formal education is extremely important to HIV prevention, given that the majority of transmissions occur among young adults.

To some extent, Taiwan and the Philippines could be considered as low HIV impact countries in Asia in terms of their current reported number of HIV cases. At the beginning of 2009, the cumulative numbers of HIV cases in Taiwan and the Philippines were 16,977 and 3,654, respectively. However, like Taiwan, the Philippines must be very much aware of the potential for an outbreak of infection among injecting drug users (IDUs). Between 
2000 and 2005, neighbouring Asian nations that previously had low HIV prevalence, such as Vietnam, experienced explosive spreads of the disease due primarily to injecting drug use, according to UNAIDS (2008).

This article aims to address the non-formal educational strategies used in the two countries. It begins with an overview of the HIV epidemic in the Philippines and then in Taiwan, as these two nations face similar situations in their epidemics, with some very important distinctions. Following this overview, we describe the formal and non-formal educational activities being conducted in each country, which national and local organizations are directing to high-risk, vulnerable populations. We highlight social-structural and environmental approaches that have been integrated into the healthcare delivery systems.

The similarities that the two countries share can be extremely helpful for those designing and implementing innovative and targeted behavioural interventions for high-risk populations. Comparing the response to the AIDS epidemic in these two countries makes it possible to critically assess the strengths and weaknesses of various educational approaches to control the epidemic. Lessons learned can be shared and disseminated throughout governmental and non-governmental organizations to serve the most vulnerable populations.

\section{Background and overview of the HIV situation in the Philippines}

The Philippines is considered to be a low HIV-prevalence country, but its epidemic is considered to be hidden and growing. Ever since the first AIDS case was reported in 1984, the prevalence among adults there has remained under $0.1 \%$, according to the national Department of Health (Philippines DOH 2005). From 1984 to 2009, the total number of reported cases was 3,654 (Philippines DOH 2009), but this figure may be inaccurate due to underreporting, as the United Nations estimates 6,000-11,000 cases (UNAIDS 2008). Table 1 shows the annual number of HIV and AIDS cases with combined numbers for 1984 to 2004, and annual numbers by major routes of transmission from 2005 to January 2009. Heterosexuals account for the highest number of cases in the Philippines; the second highest risk group is men who have sex with men (MSM)/bisexuals. The number of heterosexual transmissions has remained fairly stable during this period (about 137 new cases per year), but we see a significant and annually rising increase among MSM and bisexuals.

Table 1 Number of HIV/AIDS cases reported in the Philippines, January 1984-January 2009, by route of transmission $(N=3,654)$

\begin{tabular}{lrrrrrrr}
\hline & $1984-2004$ & 2005 & 2006 & 2007 & 2008 & 2009 & Total \\
\hline Heterosexual & 1,375 & 131 & 193 & 139 & 160 & 23 & 2,021 \\
Homosexual & 385 & 47 & 81 & 107 & 215 & 23 & 858 \\
Bisexual & 116 & 14 & 26 & 74 & 127 & 18 & 375 \\
Other & 324 & 18 & 9 & 22 & 26 & 1 & 400 \\
Blood/blood products & $(17)$ & $(2)$ & $(0)$ & $(0)$ & $(0)$ & $(0)$ & $(19)$ \\
Injecting drug use & $(6)$ & $(1)$ & $(0)$ & $(0)$ & $(1)$ & $(0)$ & $(8)$ \\
Needle prick injury & $(3)$ & $(0)$ & $(0)$ & $(0)$ & $(0)$ & $(0)$ & $(3)$ \\
Mother-to-child & $(33)$ & $(0)$ & $(4)$ & $(8)$ & $(2)$ & $(1)$ & $(48)$ \\
Unknown & $(265)$ & $(15)$ & $(5)$ & $(14)$ & $(23)$ & $(0)$ & $(322)$ \\
Total & 2,200 & 210 & 309 & 342 & 528 & 65 & 3,654 \\
\hline
\end{tabular}

Source: Philippines DOH (2009); 2009 data is only for January 
According to the National Epidemiology Center at the Department of Health, 65 new HIV cases were reported in January 2009. This is the highest number ever reported in a month in the Philippines, and represents a $63 \%$ increase over the 40 cases reported in January 2008. Young people aged 15-24 are the age group most vulnerable to HIV infection in the Philippines (Alesna-Llanto and Raymundo 2005), and sexual contact (at $89 \%$ ) is the leading mode of transmission (Philippines DOH 2009). According to the Philippines National AIDS Council (PNAC 2008), the prevalence of HIV is $0.08 \%$ among the populations identified as most at risk: registered and non-registered female sex workers (FSWs) and their clients, along with MSMs, and IDUs. However, consistent condom use among high-risk groups was low (under 30\%) according to a 2003 Behavioural Sentinel Surveillance (PNAC 2003).

In the Philippines, Cebu City has the highest number of IDUs; in 1995 it became the first site of a harm-reduction program (HRP) (PNAC 2008). An integrated HIV behavioural and serological surveillance revealed that $52 \%$ of IDUs in Cebu City had shared needles at their last injection (Philippines DOH 2007), and this figure may be as high as $77 \%$ (Mateo et al. 2004; Philippines DOH 2003). The risk appeared high though this population generally knows that this practice can lead to infection.

In the Philippines, the National AIDS and STI Prevention and Control Program began within the DOH in 1988. In 1992, the government formed the PNAC, a policy-making body with members from government agencies, nongovernmental organizations (NGOs), and professional groups, and representatives of people living with HIV. In 1998, Congress passed Republic Act No. 8504, the Philippines AIDS Prevention and Control Act, which mandates a nationwide implementation of policies and measures to prevent and control the disease (PNAC 2008; Republic Act No. 8504 1998). A fourth AIDS Medium-Term Plan, 20052010, published by the PNAC (2003), outlines five key strategies that focus on strengthening and institutionalizing interventions. They are: (1) strategies targeting highly vulnerable groups (sex workers and their clients, IDUs, and MSMs), and overseas Filipino workers (OFWs); (2) institutional and general public preventive interventions; (3) the quality of treatment, care, and support services for people infected with and affected by HIV/AIDS, (4) stigma-reduction measures and efforts to integrate them into preventive treatment, care, and support services and into the design of management systems; and (5) management systems that support the delivery of HIV/AIDS information and preventive services (p. 18).

\section{Background and overview of the HIV/AIDS situation in Taiwan}

In 1984, the first HIV infection, a foreigner in transit, was identified; in 1988, the first case of HIV infection contracted through injecting drug use was identified. In 1989, Taiwan established a nationwide surveillance system for HIV infection. Then, on 17 December 1990, the AIDS Prevention and Control Act was formulated and promulgated. With six amendments, the Act increased the number of components addressing human rights protections; on 11 July 2007, its name was changed to the HIV Infection Control and Patient Rights Protection Act.

As of 28 February 2009, 16,977 HIV-infected people (which excluded 687 HIV-positive foreigners diagnosed in the country) had been identified in Taiwan; of that number 5,338 had developed AIDS and 2,250 had died (Taiwan CDC 2009). Based on 2003 data, the ratio between the estimated number of adult (age 15-49) infections and the number of reported infected persons was 2.4:1 (Huang et al. 2005). Hence, as of February 2009, Taiwan had an estimated 40,000 cases of HIV/AIDS out of a population of 23 million. 
Further, an analysis using cumulative statistics from 1984 to February 2009 indicated that the major age groups for HIV infection are 20-29 (38\%) and 30-39 years (35\%). Of all those infected, $91 \%$ are males and $9 \%$ females, for a ratio of infected males to infected females of 10.6:1. In addition, 36\% of all those who are infected are unemployed. The numbers contracting HIV were concentrated in several risk groups, including 6,053 IDUs (36\%), 5,337 homosexuals (31\%), 4,078 heterosexuals (24\%), and 1,257 bisexuals (7\%) (Taiwan CDC 2005).

Since 1988, all people living with HIV (PLHIV) in Taiwan received free medical treatment; since 1997, they have received free highly active antiretroviral therapy (HAART). In 2004, medical treatment for PLHIV cost NT \$250,000 (about US \$7,500) per person on average; this is 70 times the average amount spent on health care by a person in the general population (Taiwan CDC 2005).

Before 1993, the total number of HIV infections was under 500. The first 5-years national strategic plan for prevention and control of HIV/AIDS initiated in 1994 focused on disease surveillance and health education (Taiwan Department of Health [DOH] 2006). Currently, the Department of Health is implementing the fourth national strategic plan (2007-2011). The plan's three major goals are preventing and controlling HIV infection, encouraging the use of screening and counseling to modify risky behaviours, and providing appropriate health care for infected people to improve their quality of life (Taiwan DOH 2006, p. 21).

HIV-related NGOs have been established since 1992. In 2009, roughly 19 NGOs provided HIV/AIDS prevention education, counseling, anonymous testing, shelter, and care. One in particular, the Living with Hope Organization, a project of Taiwan's Society of Preventive Medicine, initiated HIV/AIDS prevention education for drug-using offenders in correctional institutions in 2004, the year when warning signs of an HIV epidemic among IDUs appeared.

The NGOs receive funding from government agencies to conduct HIV preventive education for vulnerable groups. Particularly in community settings, the NGOs reach IDUs and MSMs and train peer counselors to work with hard-to-reach populations. For instance, the NGOs reach out to the gay community, disseminate HIV/AIDS educational materials in gay venues, distribute condoms at gay bathhouses, gay bars, and public parks where gay men gather, and provide anonymous HIV testing and counseling (Twu et al. 2004).

\section{Research questions}

In this study, we compare HIV/AIDS prevention and education efforts and effectiveness in the Philippines and Taiwan. Below we outline our theoretical framework and data collection methods. Two research questions guide this work:

- What are the similarities and differences in non-formal educational activities with respect to HIV/AIDS prevention?

- What are the challenges and best practices of non-formal education to promote prevention?

\section{Theoretical framework}

The non-formal educational interventions implemented in Taiwan and in the Philippines are based on a blend of social cognitive theory at the individual level and social influence 
theory at the organizational level. According to Social Cognitive Theory (Bandura 1987), behaviour change is enhanced when individuals are trained to exercize influence over their own behaviours and their social environment. They can best make such changes when they experience interventions to heighten their awareness and knowledge, along with enhanced resources and social support. Bandura conceptualized the basic elements of social cognitive theory as consisting of personal determinants in the form of cognitive, affective, and biological factors, behaviour and the environment. In this article we examine how various programmes have applied this theoretical framework to behaviours related to HIV/AIDS, by exposing participants to interventions designed not only to promote safer sex guidelines, but also to develop individual skills and self-beliefs that would enable them to reduce risks in the face of counteracting influences (Bandura 2004).

The second theoretical framework used in this research combines power and social influence. The social psychological study of power and influence originated in the groundbreaking work of Kurt Lewin (1941), who considered power to be the possibility of inducing force on someone else. More formally, it is the maximum force that Person A can place on Person B divided by the maximum resistance that B can offer. French and Raven (1959) further developed this conceptualization of power and social influence; they defined influence as a force one person (the agent) exerts on someone else (the target) to induce a change in the target, including changes in behaviours, opinions, attitudes, goals, needs, and values. Social power was later defined as the potential ability of an agent to influence a target. Raven (1965) further classified power according to the base from which it comes and listed six types: reward, coercive, legitimate, referent, expert and informational power.

\section{Data collection}

For this study, data from Taiwan were collected from several major sources, including official HIV/AIDS surveillance statistics and the national strategic plan from the website of Taiwan's Centers for Disease Control, annual reports of prevention and education activities to the AIDS Prevention and Control Committee from 2005 to 2008, educational activities among correctional institutions provided by the AIDS NGOs, and a literature review. The current inter-ministry cooperative mechanism operates through the Executive Yuan's DOH AIDS Prevention and Control Committee, a communication platform chaired by the health minister (Taiwan CDC 2008). Since 2005, all HIV/AIDS prevention and control outcomes and activities have been reported to the committee twice a year.

Data collected in the Philippines included HIV/AIDS official surveillance statistics, country reports, and the national strategic plan from the Philippines National AIDS Council. In addition 56 interviews were conducted with key informants, including government health officials, university professors, NGO staff, establishment managers, and association representatives. Three focus groups were conducted with female entertainers in Metro Manila and Angeles City in 2006-2008.

\section{Outbreak of HIV infection among injection drug users in Taiwan}

Since 1990, mandatory HIV tests have been administered to each inmate in Taiwan, including drug-using offenders, when they are first incarcerated. Before 2001, no more 
Table 2 Newly infected HIV cases reported in Taiwan by risk group, 1984-2008

\begin{tabular}{lrlrrrr}
\hline Year/risk groups & $\begin{array}{l}\text { Heterosexuals } \\
n(\%)\end{array}$ & $\begin{array}{l}\text { Homosexuals } \\
n(\%)\end{array}$ & $\begin{array}{l}\text { Bisexuals } \\
n(\%)\end{array}$ & \multicolumn{1}{l}{$\begin{array}{l}\text { IDUs } \\
n(\%)\end{array}$} & $\begin{array}{l}\text { Others* } \\
n(\%)\end{array}$ & \multicolumn{1}{l}{$\begin{array}{l}\text { Total } \\
n(\%)\end{array}$} \\
\hline $1984-1999$ & $1,057(43.7)$ & $870(36.0)$ & $350(14.5)$ & $63(2.6)$ & $78(3.2)$ & $2,418(100)$ \\
2000 & $220(41.5)$ & $232(43.8)$ & $65(12.3)$ & $6(1.1)$ & $7(1.3)$ & $530(100)$ \\
2001 & $248(38.0)$ & $312(47.8)$ & $79(12.1)$ & $7(1.1)$ & $7(1.1)$ & $653(100)$ \\
2002 & $284(36.9)$ & $376(48.8)$ & $85(11.0)$ & $19(2.5)$ & $6(0.8)$ & $770(100)$ \\
2003 & $253(29.4)$ & $427(49.6)$ & $91(10.6)$ & $77(8.9)$ & $13(1.5)$ & $861(100)$ \\
2004 & $315(20.7)$ & $485(31.9)$ & $92(6.1)$ & $613(40.4)$ & $14(0.9)$ & $1,519(100)$ \\
2005 & $416(12.3)$ & $472(13.9)$ & $90(2.7)$ & $2,381(70.3)$ & $27(0.8)$ & $3,386(100)$ \\
2006 & $462(15.8)$ & $551(18.9)$ & $118(4.0)$ & $1,768(60.5)$ & $24(0.8)$ & $2,923(100)$ \\
2007 & $433(22.4)$ & $642(33.2)$ & $124(6.4)$ & $710(36.7)$ & $25(1.3)$ & $1,934(100)$ \\
2008 & $343(19.6)$ & $861(49.2)$ & $142(8.1)$ & $379(21.7)$ & $25(1.4)$ & $1,750(100)$ \\
$1984-2008$ & $4,031(24.1)$ & $5,228(31.2)$ & $1,236(7.4)$ & $6,023(36.0)$ & $226(1.3)$ & $16,744(100)$ \\
\hline
\end{tabular}

* Includes mother-to-child transmission, hemophiliacs, blood recipients, and unknown.

Source: Adapted from Taiwan Centers for Disease Control, Updated HIV/AIDS statistics, February 2009

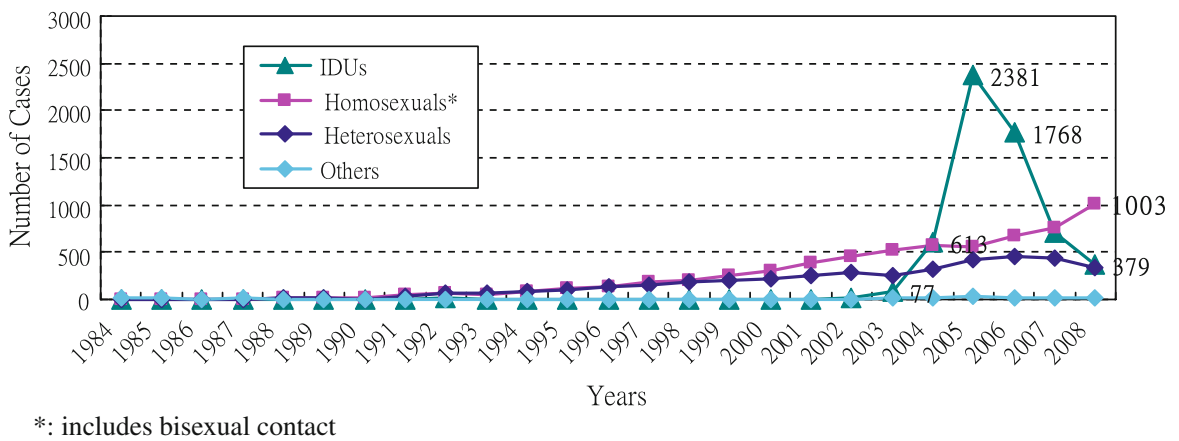

Fig. 1 New HIV infections reported in Taiwan, by risk group, 1984-2008. * includes bisexual contact. Source: Adapted from Taiwan Centers for Disease Control, HIV/AIDS Statistics, February 2009

than ten new infections among injection drug users (IDUs) were reported each year. In the past few years, however, the number of new infections among IDUs has been growing at an alarming rate (Chen and Kuo 2007). According to Ministry of Justice statistics, in 2003, the total number of infected inmates throughout Taiwan was under 80 . That number has since increased dramatically, to 419 in 2004, 1,742 in 2005, and 2,763 in 2006.

As shown in Table 2, IDUs infected with HIV in Taiwan represented only $2.6 \%$ of all HIV infections in 2002, but by 2005 they were $70.3 \%$ of the total. The number of newly infected IDUs (compared to the previous year) rose by $305 \%(58 / 19)$ in 2003, by $696 \%$ $(536 / 77)$ in 2004 , and by $288 \%(1,768 / 613)$ in 2005, as shown in Fig. 1. For Taiwanese IDUs, sharing needles/syringes and heroin diluents are major risk factors (Chen 2005). After a harm-reduction programme was launched in 2005, the proportion of IDUs infected with HIV declined to $60.5 \%$ in 2006 and then dropped dramatically, to $36.7 \%$ in 2007 (Table 2). 


\section{The success of HRPs in curbing the HIV epidemic among IDUs in Taiwan}

The harm reduction programme in Taiwan consists of three major parts: (1) information, education, and communication (IEC); (2) a needle/syringe programme (NSP); and (3) drug substitution treatment (Taiwan DOH 2005; Taiwan CDC 2007). The IEC programme expanded the HIV screening and monitoring of IDUs and provided timely health IEC to help them change their high-risk behaviours, especially the sharing of drug paraphernalia and diluents.

The NSP enabled local health departments, in conjunction with neighbourhood pharmacies and residents, to decide on where to locate operations that could provide IDUs with clean syringe paraphernalia, counseling, and health information. In November 2005, four NSP pilot projects were launched in Taipei County, Taipei City, and Taoyuan County in northern Taiwan, and Tainan County in the south. Since July of 2006, the NSP has expanded island-wide. In total, 1,103 health education and counseling service centers were set up, along with 418 vending machines providing clean needles. Roughly 8.2 million needles were given out between 1 November 2005, when the NSP was implemented, and 31 December 2008. In addition, over 777 recycling trashcans for used needles were set up, and the return rate for used needles increased from under $1 \%$ at the beginning to $80 \%$ currently; the average return rate is $61 \%$. About 5 million used needles have now been returned.

The major drug-substitution treatment programme uses methadone maintenance; it also offers follow-up counseling, education, and drug rehabilitation referrals. The first person received drug-substitution treatment on 10 February 2006, and by the end of 2008, the cumulative number of cases receiving substitution treatment was 25,683 . Island-wide, a total of 87 hospitals and clinics now provide substitution treatment services.

The HRP has successfully reversed the increase in HIV among infected IDUs. As shown in Fig. 1, the number of newly reported HIV infections among IDUs dropped from 2,455 in 2005 to 1,812 in 2006, 713 in 2007, and 379 in 2008.

\section{Successful interventions with female sex workers in the Philippines}

In a programme to prevent and control the spread of STIs, city ordinances targeted women working as freelance sex workers or in entertainment establishments and saunas. In the Philippines, Quezon City's first ordinance required all job applicants to obtain health certificates and to attend HIV/AIDS awareness seminars. In 1999, a second ordinance created an STI/AIDS Council. A third ordinance focuses on strengthening the implementation of rules and regulations that require entertainers to get weekly checkups at social hygiene clinics. Sauna and massage parlor workers attend a 1-week seminar that includes HIV awareness, personal hygiene, principles of massage, and ways to prevent HIV. Local city health department task forces monitor employees weekly for health certificates, make certain they are at least 18 years old, and check to see that the establishments have condoms. If establishments do not comply, their managers receive one warning and are advised to allow staff to comply; otherwise they face closure through due process and recommendations by the licensing and health departments.

Other cities such as General Santos and Angeles have specific activities and policies to prevent and control the spread of HIV/AIDS and other STIs. These include a policy of $100 \%$ condom use, the creation of multi-sector AIDS councils, funding for HIV/AIDS prevention activities, and a monitoring system to ensure that the sex industry complies with 
a policy prohibiting the employment of minors. Legal action has been taken to curb child prostitution in and around entertainment establishments (USAID 2008).

From 1994 to 2003, Morisky and colleagues in collaboration with the University of the Philippines (Morisky et al. 1998, 2004, 2006), collected longitudinal data from female bar workers, potential male customers, and establishment managers in the southern Philippines. The research initiative trained managers and peer educators from approximately 110 different establishments and implemented a 3-years longitudinal quasi-experimental study in four regions. The project had three parts. The teams implemented an educational policy on HIV/AIDS prevention in all intervention sites and met with city health officials at care sites to identify important recommendations that were found to significantly affect condom use behaviour and to reduce STIs. They also coordinated all intervention activities with the National AIDS Council of the Philippines, and worked closely with regional and city health departments in the four study sites. Finally, in a 3-years follow-up intervention using a crossover design for 18 organizations, they expanded this initial programme to address the educational needs of client-centered populations that female bar workers identified as their usual customers: military personnel, transportation drivers, factory workers, and members of high-risk communities.

Morisky et al. (2002b) found that both personal and situational factors were important influences on whether female bar workers used condoms. Morisky et al. (2002c) also noted that female bar workers employed in establishments that had a written policy regarding $100 \%$ condom use were 3.5 times more likely to use condoms consistently compared to establishments who had no policy. Earlier studies (Morisky et al. 1998) found that over $50 \%$ of those female bar workers expressed concerns about pain when using condoms. Further, having male clients who were substance users increased the incidence of STIs among female bar workers, while having regular partners lowered their rate of STIs (Chiao et al. 2006; Chiao and Morisky 2007). Morisky et al. (2002a) also found that STI incidence decreased when the city required karaoke bar workers to attend the SHC clinic. Sneed and Morisky (1998) discovered that attitudes and norms do predict condom use, but they are mediated by intentions.

As part of those studies, Morisky et al. (2006) conducted a multilevel analysis of the impact that a social influence intervention would have on condom use and STIs among female bar workers. The researchers contrasted the effects of peer influence, manager influence, and combined peer-manager influences on condom use and STIs; social influence models were used, which combined social cognitive theory and socio-structural theories. Female bar workers who received structural peer and establishment interventions reported more positive attitudes towards using condoms, more establishment policies favouring condom use, and fewer STIs, compared to those in either the peer-only intervention group or the control group. Those who only experienced interventions from their managers had fewer STIs, fewer negative attitudes towards condoms, and higher knowledge and perception of risk, compared to those in the peer-only intervention group. STI outcomes were measured as before-and-after comparisons (STI rates per 1,000 CSW clinic visits); those women who experienced the combined intervention (with both peer and manager) showed a significant drop in STIs, compared to those in other study groups (-21.8 difference, 36.4 to $14.6 \%$ ) (Urada et al. 2008). Also, HIV test results for the female sex workers who were registered in the study sites between June 1995 and December 2001 showed that the control group, those receiving the usual care $(N=6,157)$, had the highest number of HIV infections (10), compared to those in other study groups ( 0 for the peer intervention group, 2 for the manager intervention group, and 2 for the combined intervention group). After the intervention, it was found that those who were in the intervention 
groups and had participated for at least 3 months kept significantly more of their appointments at the clinics, compared to those in the control group $(p<0.05)$. As a result of these findings, the establishment managers formed an association and began a loan programme to increase the compliance of female bar workers to purchase and take the entire medical regimen for STIs (Morisky et al. 2002a, b, c).

Key informant interviews

A follow-up study was implemented to evaluate the diffusion effects of interventions in other areas of the Philippines and to subsequent groups of workers. Interviews with key informants in Quezon and Angeles cities and with focus groups of female bar workers in Quezon City revealed that challenges remain in other areas, especially as new employees enter the workforce at entertainment establishments.

Key informants described how some ordinances promote the policy of $100 \%$ condom use (no condom, no sex), but the informants tended to substitute phrases such as "prophylaxis devices" for condoms and "preventing illness" for "family planning" because of opposition from influential people, religious groups and because of cultural barriers.

According to these informants, freelance sex workers are especially challenging to reach. Because freelancers enter establishments to find customers, one way to identify them is to organize the registered workers and assume that the rest are freelancers. Internet cyber sex negotiations pose another challenge. The fact that freelancers can now negotiate their appointments on the Internet, using chat and text messages, makes it even harder to find them.

Another remaining challenge is to get sex workers to go to social hygiene clinics. Visits to one such clinic increased to 80 a day from the 25 a day that was standard 10 years earlier. Although fewer cases of herpes occur than in other countries such as Thailand, rates of chlamydia are high and those for gonorrhea have increased.

Key Informant interviews with staff at social hygiene clinics also revealed the difficulties of keeping track of workers' attendance at the clinics. If - but only if - a sex worker has a yellow registration card, the clinic can check if she comes back. She may also miss 1 month and return the next. Several factors account for this irregular use. First, not all managers cooperate because they are concerned about their business. Moreover, workers may not know about, or forget, their appointments. Or they may choose to see other doctors, especially if their managers arrange appointments for them.

\section{Focus groups}

Three focus groups with female entertainers revealed several continuing barriers to condom use and thus to preventing the spread of the disease:

- The women do not use condoms with boyfriends or regular partners.

- Clients offer to pay more to have sex without a condom.

- Condoms purchased at the clubs are expensive, at 100 pesos (US \$3).

- The workers spend most of their income on clothing and jewelry; any income from "ladies' drinks" goes to the establishment.

- Managers do not encourage workers to see doctors.

- The cost of a clinic visit (65 pesos) is too high; transportation is also costly.

- Many fear the common disease chlamydia the most, but may not have money to buy medication and fear that they can no longer work (most have children). 
- Entertainers are not organized among themselves; they are only registered with the City Health Department.

- They have no opportunities for peer training.

In the focus groups, the entertainers made several recommendations.

- They need counseling.

- They want more information on HIV and want to learn more about all STDs.

- They would like to see violent clients put in jail.

- They would like peer trainings to create leaders and a point person in every establishment.

\section{Non-formal educational activities in the Philippines}

In the Philippines, NGOs play a vital role in implementing HIV prevention programmes in the general population and for high-risk groups. Government agencies partner with NGOs that have access to the community, especially hard-to-reach populations. NGOs also fill the gap where pressure from the Catholic Church makes it hard for government agencies to implement sex education and to distribute contraceptive information and condoms.

On the other hand, in Taiwan, where the HIV Infection Control and Patient Rights Protection Act was promulgated and implemented in July 2007, the responsibility for carrying out HIV education is no longer confined to health authorities. Article 7 states that "competent authorities shall conduct education programmes and promotion campaigns on the prevention and control of HIV. The various central competent authorities shall devise annual plans detailing education programmes and promotion campaigns; the contents of such plans shall be sex-conscious and shall focus on anti-discrimination; the plans shall be implemented with the assistance of organizations, schools, groups and mass media." It appears that the Taiwanese government has a very positive attitude towards implementing a comprehensive campaign to educate people about HIV and AIDS and to promote prevention efforts.

Youth and HIV/AIDS education in schools

In the Philippines, NGOs complement the life skills programme that the Department of Education offers in schools. The Girl Scouts of the Philippines (GSP) is the nation's largest association of girls and young women, with a membership of over one million. Through its 95 councils in six regions, it provides information and skill-building for HIV prevention in nearly all of the nation's public elementary and secondary schools (PNAC 2008; United Nations Global Coalition on Women and AIDS 2006).

Other NGOs, such as the UN Global Coalition on Women and AIDS (2006), emphasize life skills and peer education for school-aged youth in informal educational settings. The PRIME II project, run by IntraHealth International (2003), integrates family planning and peer education with HIV prevention for high-risk youth. An annual MTV Staying Alive Music Summit delivers messages about HIV prevention and transmission to thousands of youth (Rutstein 2005).

Several other NGOs are listed in the Philippines HIV Initiatives Database, run by the Health Action Information Network (2007). For example, Advocates for Youth Philippines Foundation holds campus tours and road shows that promote education, prevention, 
enhancement of values, and life skills. The American Chamber Foundation Philippines Inc. conducts information, education, and communication sessions, refresher sessions, and a youth camp. The Children's Christian Fund holds interactive workshops and seminars on reproductive health and HIV/AIDS. The Foundation for Adolescent Development, Inc. integrates HIV/AIDS education in telephone hotline counseling in Metro Manila and lifeplanning education for out-of school youth. The Names Project Philippines, Inc. holds advocacy and education activities in partnership with the Pinoy Plus Association.

Turning to Taiwan, in its school systems, education about the disease is part of the Chun-Huei ("spring sunshine") Project, the substance abuse and HIV/AIDS prevention project which the Ministry of Education (MOE) has implemented since 1991. The project encourages schools at all levels, from primary to college, to conduct annual educational activities focused on the disease as well as on preventing substance abuse. Students' ChunHuei clubs receive annual subsidies from the MOE to conduct extracurricular educational activities, like poster contests. In addition, the Taiwan AIDS Foundation has recently reached out to schools with education to prevent HIV.

In 2007, to coordinate with the HIV Harm Reduction Pilot Programme for IDUs, the DOH asked the MOE to establish drug abuse and HIV prevention as a learning indicator in the Health and Physical Education programme in the curriculum guidelines for Grades 1 through 9. For high schools, sessions on drug abuse prevention and control and on HIV prevention were incorporated into the course guidelines on Health and Nursing and Citizens and Society; these enable youth in the formal educational system to learn how to prevent the spread of the disease.

\section{Populations with the highest prevalence in Taiwan and the Philippines}

Four groups experience particularly high prevalence of the disease: Taiwanese users of injected drugs, Filipinos who work overseas, men who have sex with men, and women, especially in the Philippines.

Taiwanese injected drug users

In Taiwan, two campaigns of health education and promotion are targeted at IDUs, at both the community level and in the criminal justice system. The HRPs, mentioned earlier, serve IDUs in their communities. They are implemented through neighbourhood pharmacies, clinics, and 87 referring hospitals throughout the country which provide clean syringes, counseling, health information, and long-term oral methadone maintenance treatment. Since 2006, such programmes have also been directed at IDUs in the criminal justice system, provided by local health departments and NGOs. In 2008, local police focused on illegal prostitutes, sex consumers, pimps, and suspected drug users; when they found such people, they immediately notified the local health departments so that medical staff could conduct blood screening and teach them about the disease. Between January and September of 2008, the police recorded 28,648 arrests of suspected drug users.

The Philippines also has needle- and syringe-exchange programmes; they started in 1995 in Cebu City (PNAC 2008; Ball et al. 1998). Currently, 800 IDUs receive prevention services and clean needles/syringes at three major outreach locations. Antiretroviral treatment has been provided free since 2005, and the STI AIDS Cooperative Central Laboratory offers a baseline CD4 count for free. Recently, 390 PLHIV were enrolled for drug treatment and were receiving extended care and support services (Mesquita et al. 
2008; Asian Development Bank 2007). Together, NGOs, local health departments, and stakeholders provide harm-reduction services, including outreach, peer education, psychosocial support, provision of clean needles and syringes, and treatment for STIs and other health-related concerns.

\section{Overseas Filipino workers}

In the Philippines, overseas workers have a higher incidence of the disease than any other group: 1,196 cases, or 33\% of all reported cases from 1984 to January, 2009, according to the Philippines DOH National Epidemiology Center (2009). Of these workers, 95\% contracted HIV through sexual intercourse, and $75 \%$ are males. OFWs are required to attend a seminar on the cause, prevention, and consequences of HIV/AIDS before they can be certified for their overseas assignments. The DOH offers them voluntary counseling and testing after they return from abroad.

Founded in 2000, the Action for Health Initiatives (ACHIEVE), Inc., a non-profit organization based in Quezon City, targets migrant workers and their families, specifically addressing their sexual and reproductive health, rights, and HIV vulnerability. ACHIEVE is a member of the Coordination of Action Research on AIDS and Mobility in Asia (CARAM-Asia), a regional network of organizations working on migration and HIV/AIDS issues in the Asian region.

During a pre-departure orientation seminar run by the Foreign Service Institute of the Department of Foreign Affairs (DFA), ACHIEVE provides information about HIV and AIDS and guidelines for OFWs on how to handle cases of HIV and AIDS on the job. Seafarers are tested regularly. Another NGO, LIKHAAN, also conducts HIV/AIDS education in pre-departure seminars conducted by the Overseas Welfare Association.

Men who have sex with men

The majority of people in conservative Asian societies like Taiwan do not accept sex between men, so men who have sex with men often face discrimination. Consequently, many MSM do not want to reveal their sexual orientation-which makes it very difficult for health authorities to reach them with their HIV-prevention programmes. NGOs can do so more effectively. From August to October 2008, the CDC sponsored the Light of Friendship Association of Taiwan to carry out rapid HIV-screening services at venues and locations where homosexuals tend to congregate in Taipei, Taichung, and Kaohsiung. In 1992, the Ministry of the Interior included testing for syphilis and HIV as part of the physical examination for those entering the military.

NGOs are also important in the Philippines, especially in carrying out outreach activities that target MSMs at the local level. The Butterfly Brigade, an NGO in the Boracay region of the Philippines, is described as a model for peer education groups for MSM communities. The gay community initiated the NGO themselves by holding informal group discussions. From these discussions, they discovered a need for health services targeting their community. The NGO influenced the regional health system to offer condom promotion, voluntary testing, counseling, and care, and to install condom vending machines in the tourist city's pickup spots. Gay-sensitive educational programmes incorporated participatory and interactive music, visuals, beauty contests, and timed interventions from 8 p.m. to 2 a.m., the time when many gay men cruise for sex. The number of MSMs seeking help at social hygiene clinics increased (PNAC 2008). 
Women

Women are at high risk in the Philippines; they account for nearly $30 \%$ of all the cases of HIV since 1984 (Philippines DOH 2009). The highest prevalence is among women aged 20-39. Over $25 \%$ of women in the women's state penitentiary in Metro Manila were infected with STIs (Simbulan et al. 2001). In the general population, Avelino et al. (1997) found that residents in Quezon City, aged 15-49, had a high level of awareness of HIV/ AIDS, but only $32 \%$ had used a condom during their most recent intercourse with a nonregular partner, and $28 \%$ of IDUs shared their injection equipment with others. These findings indicate that women in the general population face some risk.

Targeting high-risk females such as entertainment establishment workers, the Philippines government's Technical Skills and Development Authority office conducted livelihood programmes at some social hygiene clinics. Nurses and doctors at the clinics gave lectures on health education, and all NGOs were invited to provide services there. And, through its work at the clinic, an NGO called Belen hired a commercial sex worker who decided to find different work.

In Taiwan, as statistics from the CDC indicate, far more men than women were being infected: in 2003, the male-to-female ratio of newly reported cases was 20:1. Soon, however, infection among women increased rapidly. In 2006, the male-to-female ratio for newly reported cases rose to 7.4:1, but in 2008 it fell to 16.9:1. In Taiwan, most women who contract the disease do so through their sex partners, as sex workers, or through using injection drugs. At the end of February 2009, 41.57\% of all HIV-infected women were between 20 and 29 years old (Taiwan CDC 2009). Women of childbearing age who are vulnerable to the disease need to get tested, especially if they have had an STD, are sex workers or IDUs, had multiple sex partners while pregnant or an HIV-infected sex partner, or if they engage in other high-risk behaviours. Early intervention and prevention of HIV infection among these vulnerable high-risk groups can prevent the spread of HIV, both horizontally and vertically. Consequently, since 2006, the DOH has included routine HIV screening in prenatal examinations. In addition, when police arrest illegal prostitutes, they immediately notify the local health department, which in turn conducts blood screening and connects the woman to a HIV health education and promotion campaign. Between January and September of 2008, police made 2,289 arrests of illegal prostitutes.

\section{Comparative data on combating the epidemic in Taiwan and in the Philippines}

Table 3 summarizes the comparative data on the targeted approaches, both structural and environmental, that both countries are implementing to stem the AIDS epidemic. Agencies of both governments were very active in promoting national strategic plans as the epidemic began. They also initiated sentinel epidemiological surveillance early on, in order to identify and implement educational approaches tailored to those specific high-risk groups. Minor differences can be seen in the handling of mandatory blood testing among high-risk groups: blood testing is mandatory for all those entering prisons in Taiwan, while the Philippines only has local government ordinances for testing and counseling.

The two countries differ in approaches for working with the highest targeted HIV risk groups. Taiwan focuses on IDUs and MSM, whereas the highest risk group in the Philippines is overseas contract workers and the disease is mostly transmitted through heterosexual contact. Both countries have harm reduction programmes, but Taiwan's is more widespread, given the larger numbers of infected IDUs. Taiwan focuses on pregnant 


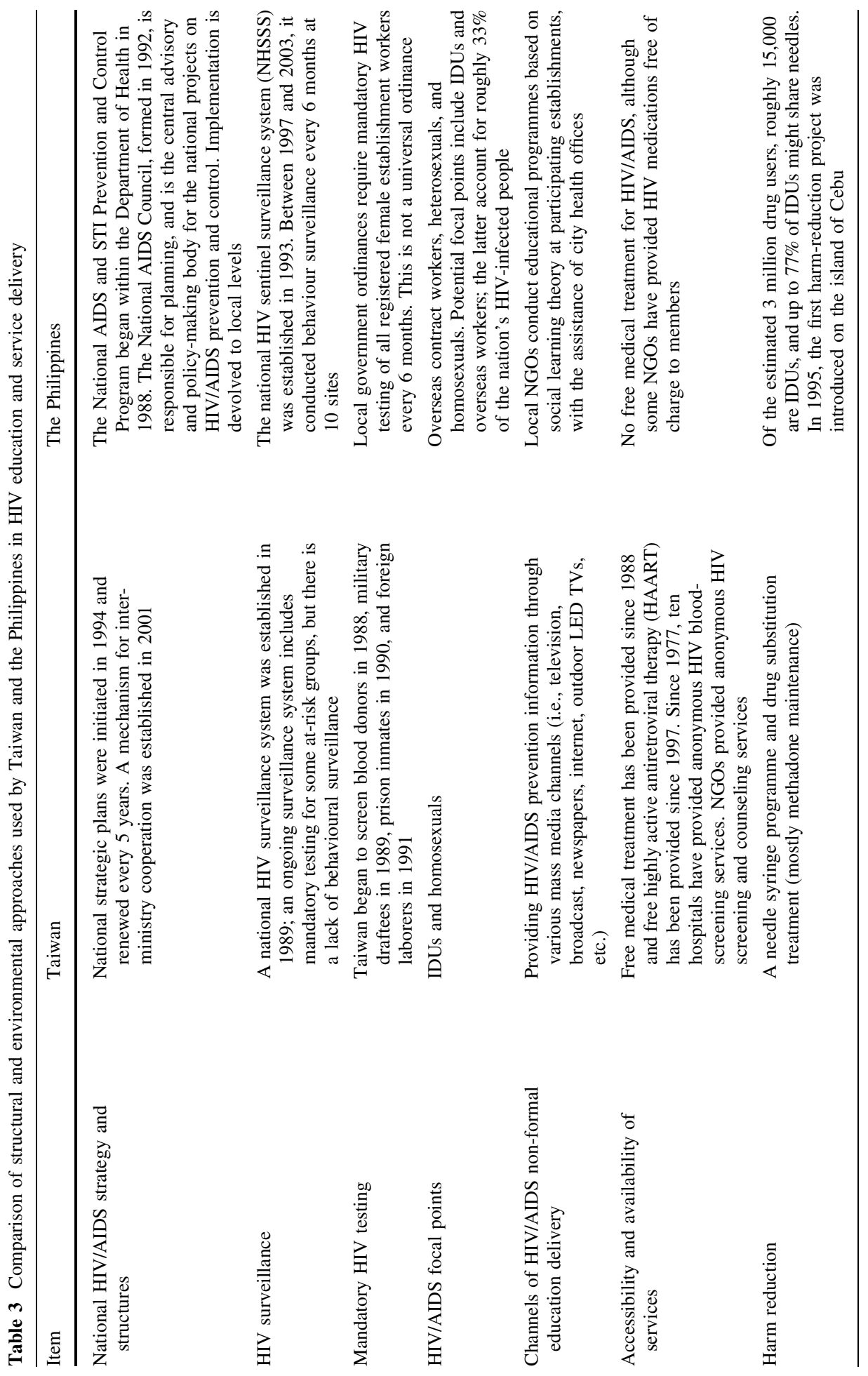




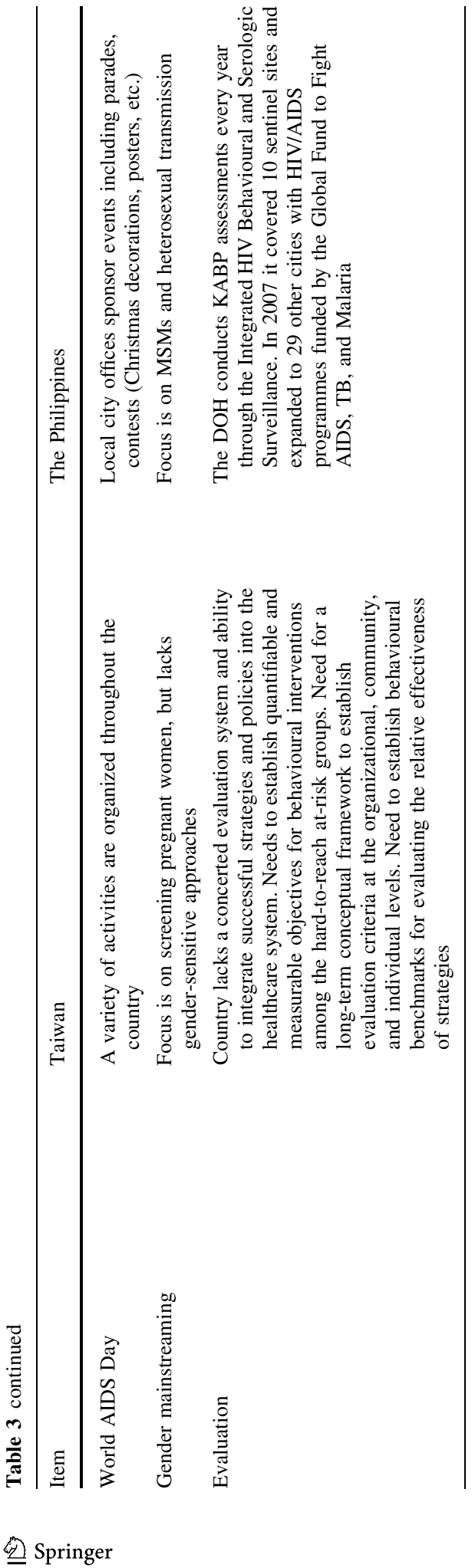


women, while the Philippines has moved away from funding programmes to prevent mother-to-child transmission, as the levels of such transmission have dropped. Instead, the focus is now on the rising prevalence among MSMs. Among IDUs the disease entered Taiwan like a thief in the night; in the 3 years from 2003 to 2005, the rate of infection rose by an unprecedented 30 -fold. This drastic increase should serve as a wake-up call to the Philippines which could see a similar rise in its number of infected IDUs; especially if they continue to share drug paraphernalia, a pool of infections among IDUs could become a reality.

Looking at channels for non-formal services, both Taiwan and the Philippines rely heavily on government collaboration with NGOs at the local levels. Noteworthy is Taiwan's focus on mass media delivery. World AIDS Day is recognized in both countries, but antiretroviral medication and treatment for people who are HIV positive is offered more freely in Taiwan than in the Philippines. Taiwan does not yet have a dedicated evaluation component like the integrated evaluation system that the Philippines Department of Health conducts through its National Epidemiology Center.

\section{Discussion}

Parkhurst (2008) examines "what works" in driving down the prevalence of the disease, and lists these five elements: falling HIV prevalence, fewer new infections, changes in behaviour, causes of behaviour change, and responsible policies.

Earlier studies involving sentinel surveillance in major regions of the Philippines provide an empirical basis for the very low HIV prevalence. However, national implementation of policy is devolved to local government levels, and many programmes are delivered by NGOs. This can be both beneficial and problematic, as community resources ensure that delivery systems continue, but few programmematic evaluations are conducted.

Over the past 5 years, the number of new cases reported to the Philippines HIV registry has begun to rise steadily. The government has placed a priority on outreach and services to overseas workers and IDUs as a result of the increased prevalence of unprotected sex among highly vulnerable groups (PNAC 2003).

Service provision to overseas workers is an example of a best practice by the Philippines government. These workers, and their significant others, receive IEC, pre-departure seminars, and voluntary HIV testing and counseling upon their return. However, few empirical studies have examined the effectiveness of these approaches.

Also, efforts to reach the broader community have been made at various other worksites (Morisky et al. 2004), and within both the army and schools. The government relies on non-formal educators and NGOs to implement many of these activities.

The PNAC aims to promote $100 \%$ condom use and behavioural change communication in every prevention effort, to encourage partnerships between local governments and NGOs, and to establish local AIDS councils. Some key cities have implemented the $100 \%$ condom use policy (UNAIDS 2008). But not all local governments have adopted these efforts. HIV has remained low among female sex workers; one explanation is the government's early and continuing strategy of monitoring and treating STIs through its social hygiene clinics. As in Taiwan, prostitution is illegal in the Philippines. However, the Philippines health system requires all workers at entertainment establishments to register with the government and to receive regular STI health check-ups at the government clinic. Outreach, treatment, and regular screening of sex workers in the Philippines have led to STI declines among sex workers and their clients (Wi et al. 2006). Rules on condom use at 
entertainment establishments may also make a difference; in one study, workers were 2.6 times more likely to use condoms consistently when the establishment had such a rule (Morisky et al. 2002a, b, c).

Challenges remain for the Philippines. NGOs deliver psycho-social and medical services for IDUs. However, the Philippines could experience a rapid increase in HIV due to the use of injecting drugs, as happened in Taiwan. The Philippines National AIDS Council plans to expand HRPs to other areas where the numbers of IDUs are increasing. As part of a national surveillance system, 360 male IDUs were surveyed in Cebu City, Philippines, from 1997 to 1999. Although most of the men knew that certain behaviours put them at risk, more than two-thirds reported they shared needles and almost two-thirds of those who were sexually active said they never used condoms (Amadora-Nolasco et al. 2002). Other challenges include a conservative culture that discourages open discussion of sexuality, inadequate social and behavioural research and monitoring, high numbers of STIs, and the weak integration of HIV/AIDS programmes into local governments (UNAIDS 2008). Finally, the low rate of HIV testing among both the general and high-risk populations in the Philippines poses a major problem for detection and early treatment (PNAC 2008).

In Taiwan, several concerns have arisen about the HRPs, although they are considered an example of good HIV prevention practice. Several studies have shown that HRPs are effective in decreasing HIV prevalence among criminal justice populations (Lan and Chen 2007, 2008; Chen et al. 2008). Lan and Chen (2008) found that after an HRP was conducted in the northern region of Taiwan at the end of 2005, the HIV prevalence decreased from 37.6 to $18.7 \%$ in the detention center within 6 months. In contrast, the prevalence rose by 1.4 and $3.7 \%$, respectively in the central and southern regions where no HRPs were conducted during that period. Significant differences were found between these regions in terms of the change in HIV prevalence. Moreover, the HIV antibodypositive rate among returned syringes also decreased significantly, from 18.0 to $9.4 \%$ $(p<0.001)$ in 2007.

The significant decrease in the numbers of new cases among IDUs is evidence that HRPs have succeeded in curbing the epidemic. However, the role of non-formal education should not be ignored. The HIV epidemic began in 2004, but the pilot HRP was launched in November 2005 with limited access to drug substitution treatment, and then became nationwide after a 6-months trial. Needles and syringes are very easy to purchase in Taiwan, even without needle syringe programmes. Hence, non-formal education was also a key factor in this success. The rapid increase in the HIV epidemic caused greater media attention and increased reporting. Also, over $60 \%$ of the new reports of infections were among the incarcerated population and resulted from mandatory HIV testing. Segregating the HIV-infected prisoners prevented them from spreading the virus. Furthermore, NGOs began voluntary HIV prevention health education programmes in correctional institutions in 2004. Ko et al. (2009) found that, for drug-dependent inmates, a brief HIV education programme based on a transtheoretical model was effective.

At one time, up to half of IDUs commonly shared needles and syringes (Lyu et al. 1999). A recent study indicated that following the SARS outbreak in Taiwan an increase in sharing of needles may have helped cause the rapid increase of infections among IDUs; they may have engaged in more of this risky sharing behaviour because of a perceived decrease in the drug supply during the outbreak (Lyu et al. 2008).

Previous studies have found that marketing HRPs in correctional institutions requires a culturally sensitive approach to increase the incentives for participation. In 2006 and 2007, Chen et al. (2008) surveyed 2,239 new inmates in jails; they found that 694 were IDUs. Among those IDUs, 67 were PLHIV. In total, 56.6\% of the IDUs had heard of harm 
reduction, but only $8 \%$ of the PLHIV had ever participated in a syringe-needle exchange programme. More than $51 \%$ had left their used needles in trash cans or gutters.

Education is the most important factor in behaviour change, especially in a situation as complex as the HIV epidemic. Ironically, in Taiwan, once the epidemic among IDUs was controlled, a hidden epidemic among homosexuals (including bisexuals) became apparent. The number of newly HIV-infected homosexuals increased steadily, from 472 (14\%) in 2005 to 861 (49\%) in 2008, as shown in Table 2. In other words, approximately half of the newly reported infections occurred among homosexuals. This suggests the need to deliver appropriate messages to that group, using culturally sensitive and gender-sensitive approaches. Developing an appropriate non-formal educational approach to the MSM group might become the next challenge now that the high incidence among IDUs has been reduced.

\section{Conclusions}

In summary, the non-formal educational programmes in each country highlight the importance of environmental factors and their predictive ability in modifying HIV prevention behaviours among FSWs in the Philippines and IDUs in Taiwan. The results underscore the importance of developing structural and organizational interventions to prevent HIV/STDs. In addition to improving knowledge, efficacy, and skills related to needle use and safe sexual practices, health workers involved in these non-formal educational activities should work closely with community gatekeepers to create a supportive environment for HIV prevention.

Both countries have the special features of inter-ministry cooperation and HIV surveillance. Taiwan has several mandatory HIV testing practices among target groups such as inmates, and the Philippines has a sentinel surveillance programme. These serve as important bases for conducting needs assessments and for implementing non-formal education. The inter-ministry cooperation increases access to vulnerable groups and hardto-reach populations. The surveillance helps identify populations at risk. A notable strength of the Philippines in preventing HIV transmission is its system of registering sex workers, which enhances the non-formal education for this vulnerable group. A strength of Taiwan is its provision of free HAART to encourage voluntary testing. The mission of non-formal educational efforts should be disseminating knowledge and skills to prevent the disease's spread, and to increase service utilization.

Worldwide, most independent countries have implemented compulsory education; children are required to attend school for a given period of time (Benavot 2002). With respect to HIV prevention, non-formal educational activities play an important role for children who drop out of school or do not have the opportunity to attend as well as for the adult population and vulnerable groups. The education of female bar workers in the Philippines (Morisky et al. 2005) and the HIV education in the correctional systems for IDUs in Taiwan (Ko et al. 2009) are examples of best practices for designing, implementing, and evaluating non-formal educational programmes. Both countries draw upon the assistance of NGOs to carry out non-formal educational activities.

Our analysis leads to six suggestions for policy:

1. Individual behavioural surveillance should be conducted regularly with at-risk groups to monitor behaviour that could lead to HIV infection as well as for priority setting. 
2. Organizational efforts at behaviour change must establish normative standards regarding regular attendance at local social hygiene clinics and training of peer educators in establishments and worksites, as well as in the prison system.

3. Non-formal education must focus on delivering appropriate messages to the target audience, using approaches that are both culturally sensitive and gender-sensitive.

4. More intervention research should be encouraged to target vulnerable groups, as in the testing of incarcerated injection drug users and condom use among female bar workers.

5. Indicators of programme effectiveness should be developed for implementation, followed by empirical studies to provide evidence of success, e.g., HRPs.

6. Highly motivated IDU inmates should be trained as peer counselors who can serve as outreach health education workers in their communities upon release.

Acknowledgments This research was supported by Grant R01-AI33845 from the National Institute of Allergy and Infectious Diseases to Donald E. Morisky, and by the UCLA Graduate Division Doctoral Training Program in the Social and Behavioral Determinants of HIV/AIDS Prevention, the University of California Office of the President Pacific Rim Research Program, and the UCLA International Institute. We extend appreciation to our co-investigator Dr. Teodora Tiglao; our research manager, Charlie Mendoza; our site coordinators, Dorcas Romen, Grace Carungay, Angelica Mallari, Mildred Publico, and Grace Ong, and to our co-investigators in the follow-up study, Ma. Theresa Cubero, Laufred I. Hernandez, Dr. Nymia Pimentel-Simbulan, Dr. Reynaldo Imperial, Benilda Deguia and the Philippines Rural Reconstruction Movement, Inc. Special thanks to the Ministry of Education, Ministry of Justice, and Centers for Disease Control, Department of Health, Executive Yuan in Taiwan for providing data.

Open Access This article is distributed under the terms of the Creative Commons Attribution Noncommercial License which permits any noncommercial use, distribution, and reproduction in any medium, provided the original author(s) and source are credited.

\section{References}

Akani, C. I., \& Erhabor, O. (2006). Rate, pattern and barriers of HIV serostatus disclosure in a resourcelimited setting in the Niger delta of Nigeria. Tropical Doctor, 36(2), 87-89.

Alesna-Llanto, E., \& Raymundo, C. M. (2005). Contraceptive issues of youth and adolescents in developing countries: Highlights from the Philippines and other Asian countries. Adolescent Medicine Clinics, 16(3), 645-663.

Amadora-Nolasco, F., Alburo, R. E., Aguilar, E. J. T., \& Trevathan, W. R. (2002). Knowledge and perception of risk for HIV and condom use among male injecting drug users in Cebu City, Philippines. Drug and Alcohol Review, 21(2), 137-143.

Asian Development Bank. (2007). Subproject 5: Strengthening country response to HIV/AIDS among highrisk groups in the Philippines (Financed by the Cooperation Fund for Fighting HIV/AIDS). Technical Assistance Report. Manila: ADB. http://www.adb.org/.

Avelino, F. L., Abad-Viola, G. B., Magboo, F. P., Badoy, T. J., Roces, M. C. R., \& Dayrit, M. M. (1997). HIV prevention indicators in Quezon City, Philippines. Journal of Clinical Epidemiology, 50(Suppl 1), $27 \mathrm{~S}-27 \mathrm{~S}(1)$.

Ball, A. L., Rana, S., \& Dehne, K. L. (1998). HIV prevention among injecting drug users: Responses in developing and transitional countries. Public Health Reports, 113(Suppl 1), 170-181.

Bandura, A. (1987). Perceived self-efficacy in the exercise of control over AIDS infection. Paper presented at the NIMH drug abuse research conference on women and AIDS, Bethesda, MD.

Bandura, A. (2004). Health promotion by social cognitive means. Health Education and Behavior, 31(2), $143-164$.

Benavot, A. (2002). A critical analysis of comparative research. Prospects, 32(1), 51-73.

Chen, Y. M. (2005). Molecular epidemiology of HIV-1 infection among injecting drug users in Taiwan. Paper presented at the 2005 Taipei international conference on drug control and addition treatment, Taipei, Taiwan. 
Chen, Y. M., \& Kuo, H. S. (2007). HIV-1 in Taiwan. The Lancet, 369(9562), 623-625.

Chen, Y. M., Lan, Y. C., Lu, C. L., \& Chen, K. H. (2008). Impact of a harm reduction program on the prevention of HIV-1 infection among injecting drug users in Taiwan. Paper presented at the 2008 harm reduction 2008 conference, 19th international IHRA conference, Barcelona, Spain.

Chiao, C., \& Morisky, D. E. (2007). The role of a regular sex partner in sexually transmitted infections and reinfections: Results from the study of female entertainment establishment workers in the Philippines. Sexually Transmitted Diseases, 34(8), 534-540.

Chiao, C., Morisky, D. E., Rosenberg, R., Ksobiech, K., \& Malow, R. (2006). The relationship between $\mathrm{HIV} /$ sexually transmitted infection risk and alcohol use during commercial sex episodes: Results from the study of female commercial sex workers in the Philippines. Substance Use and Misuse, 41(10-12), 1509-1533.

Claeson, M., \& Alexander, A. (2008). Tackling HIV in India: Evidence-based priority setting and programming. Health Affairs, 27(4), 1091-1102.

Davis, D., Barrington, T., Phoenix, U., Gilliam, A., Collins, C., Cotton, D., et al. (2000). Evaluation and technical assistance for successful HIV program delivery. AIDS Education and Prevention, 12(2), $115-125$.

Ellis, P. (1995). Non-formal education and empowerment of women: Insights from the Caribbean. Convergence, 28(3), 86-96.

Evans, D. R. (1981). Ghana and Indonesia: Reforms in non-formal education at the community level. Prospects, 11(2), 225-241.

French, J. R. P., Jr., \& Raven, B. H. (1959). The bases of social power. In D. Cartwright \& A. F. Zander (Eds.), Studies in social power (pp. 150-167). Ann Arbor, MI: Institute for Social Research.

Gollub, E. L. (2008). A neglected population: Drug-using women and women's methods of HIV/STI prevention. AIDS Education and Prevention, 20(2), 107-120.

Health Action Information Network (2007). Philippines HIV Initiatives database. Philippine National AIDS Council. http://hivmephilippines.blogspot.com/.

Hearst, N., Mandel, J. S., \& Coates, T. J. (1995). Collaborative AIDS prevention research in the developing world: The CAPS experience. AIDS, 9(Suppl 1), S1-S5.

Huang, Y. F., Huang, Y. S., Pan, L. C., Hsieh, Y. W., Lin, C. H., Wang, S. H., et al. (2005). An estimated prevalence rate of adult (15-49) HIV infection in Taiwan till year 2003. Formosan Journal of Medicine, 9(6), 713-721.

IntraHealth International (2003). Philippines: Integrating family planning with HIV prevention for high-risk youth. PRIME Voices \#25. http://www.intrahealth.org/.

Jacob, W. J., Morisky, D. E., Hite, S. J., \& Nsubuga, Y. K. (2006). Evaluation of HIV/AIDS education programmes in Uganda. In D. E. Morisky, W. J. Jacob, Y. K. Nsubuga, \& S. J. Hite (Eds.), Overcoming AIDS: Lessons learned from Uganda (pp. 63-84). Greenwich, CT: Information Age Publishing.

Ko, N. Y., Hsu, S. T., Chen, C. H., Tsai, C. Y., Chu, P. J., Huang, C. J., et al. (2009). A pilot study of HIV education on readiness to change on substance use, AIDS knowledge, self-efficacy for risk reduction among male drug-dependent inmates. Substance Use and Misuse, 44(3), 322-331.

Lan, Y. C., \& Chen, Y. M. (2007). Prevalence of HIV infection among injecting drug users in Taiwan in the beginning of harm reduction program. Paper presented at the 4th IAS conference on HIV pathogenesis, treatment and prevention, Sydney, Australia.

Lan, Y. C., \& Chen, Y. M. (2008). Evaluation of the harm-reduction program in Taiwan. Paper presented at the 17th international AIDS conference, Mexico City, Mexico.

Latkin, C. A., Donnell, D., Metzger, D., Sherman, S., Aramrattna, A., Davis-Vogel, A., et al. (2009). The efficacy of a network intervention to reduce HIV risk behaviours among drug users and risk partners in Chiang Mai, Thailand and Philadelphia, USA. Social Science and Medicine, 68(4), 740-748.

Lewin, K. (1941). Analysis of the concepts whole, differentiation, and unity. University of Iowa Studies in Child Welfare, 18, 226-261.

Lyu, S. Y., Peng, E. Y., Chen, Y. M., Morisky, D. E., \& Cheng, S. H. (2008). Potential causes of rapid increase of HIV infection among injection drug users after SARS outbreak in Taiwan. Poster session presented at the 9th Taipei international conference on HIV/AIDS, Taipei, Taiwan.

Lyu, S. Y., Tsai, S. T., Wu, C. I., Tsai, C. N., Tsao, K. W., \& Lin, H. C. (1999). Drug abuse behavior and mental health status among intravenous drug-using parolees in Taipei County. Chinese Journal of Mental Health, 20(2), 67-86.

Mantell, J. E., Stein, Z. A., \& Susser, I. (2008). Women in the time of AIDS: Barriers, bargains, and benefits. AIDS Education and Prevention, 20(2), 91-106.

Mateo, R., Jr., Sarol, J. N., Jr, \& Poblete, R. (2004). HIV/AIDS in the Philippines. AIDS Education and Prevention, 16(3 Suppl A), 43-52. 
Mesquita, F., Jacka, D., Ricard, D., Shaw, G., Tieru, H., Yifei, H., et al. (2008). Accelerating harm reduction interventions to confront the HIV epidemic in the Western Pacific and Asia: The role of WHO (WPRO). Harm Reduction Journal, 5, 26. doi:10.1186/1477-7517-5-26.

Morisky, D. E., Ang, A., Coly, A., \& Tiglao, T. V. (2004). A model HIV/AIDS risk reduction programme in the Philippines: A comprehensive community-based approach through participatory action research. Health Promotion International, 19(1), 69-76.

Morisky, D. E., Ang, A., \& Sneed, C. (2002a). Validating the effects of social desirability on self-reported condom use. AIDS Education and Prevention, 14(5), 351-360.

Morisky, D. E., Chiao, C., Stein, J. A., \& Malow, R. (2005). Impact of social and structural influence interventions on condom use and sexually transmitted infections among establishment-based female bar workers in the Philippines. Journal of Psychology and Human Sexuality, 17(1), 45-63.

Morisky, D. E., Peña, M., Tiglao, T. V., \& Liu, K. Y. (2002b). The impact of the work environment on condom use among female bar workers in the Philippines. Health Education and Behavior, 29(4), 461-472.

Morisky, D. E., Stein, J., Chiao, C., Ksobiech, K., \& Malow, R. (2006). Impact of a social influence intervention on condom use and sexually transmitted infections among establishment-based female sex workers in the Philippines: A multilevel analysis. Health Psychology, 25(5), 595-603.

Morisky, D. E., Stein, J. A., Sneed, C. D., Tiglao, T. V., Tempongko, S. B., Baltazar, J. C., et al. (2002c). Modeling personal and situational influences on condom use among establishment-based commercial sex workers in the Philippines. AIDS and Behavior, 6(2), 163-172.

Morisky, D. E., Tiglao, T. V., Sneed, C. D., Tempongko, S. B., Baltazar, J. C., Detels, R., et al. (1998). The effects of establishment practices, knowledge and attitudes on condom use among Filipina sex workers. AIDS Care, 10(2), 213-220.

Parkhurst, J. O. (2008). "What worked?": The evidence challenges in determining the causes of HIV prevalence decline. AIDS Education and Prevention, 20(3), 275-283.

Philippines Department of Health (2003). Status and trends of HIV/AIDS in the Philippines. The 2002 technical report of the National HIV/AIDS Sentinel Surveillance System. Manila: DOH.

Philippines Department of Health, National Epidemiology Center (2005). The 2005 Integrated HIV Behavioral and Serologic Surveillance findings. Summary Report. Manila: National Epidemiology Center, DOH.

Philippines Department of Health, National Epidemiology Center (2007). The 2007 Integrated HIV Behavioral and Serologic Surveillance findings. Summary Report. Manila: National Epidemiology Center, DOH.

Philippines Department of Health, National Epidemiology Center (2009). HIV/AIDS registry report. Manila: National Epidemiology Center, DOH.

Philippines National AIDS Council (2003). The 4th AIDS medium-term plan, 2005-2010, Philippines. Manila: Philippines National AIDS Council.

Philippines National AIDS Council (2008). Follow-up to the declaration of commitment on HIV and AIDS United Nations General Assembly Special Session (UNGASS): Country report of the Philippines, January 2006 to December 2007 (with support from the UN Theme Group on HIV and AIDS). Resource document. Manila: Philippines National AIDS Council.

Raven, B. H. (1965). Social influence and power. In I. D. Steiner \& M. Fishbein (Eds.), Current studies in social psychology (pp. 399-444). New York: Wiley.

Republic Act No. 8504 (1998). The Philippines AIDS prevention and control act of 1998. Manila: Republic of the Philippines.

Rutstein, D. (2005). The Philippines launches "Unite for Children, Unite Against AIDS". Makati City, Philippines: UNICEF. http://www.unicef.org/.

Shah, S. A., Kristensen, S., Memon, M. A., White, H. L., \& Vermund, S. H. (2007). Syndromic management training for non-formal care providers in Pakistan improves quality of care for sexually transmitted diseases STD care: A randomized clinical trial. The Southeast Asian Journal of Tropical Medicine and Public Health, 38(4), 737-748.

Simbulan, N. P., Aguilar, A. S., Flanigan, T., \& Cu-Uvin, S. (2001). High-risk behaviors and the prevalence of sexually transmitted diseases among women prisoners at the women state penitentiary in Metro Manila. Social Science and Medicine, 52(4), 599-608.

Sneed, C. D., \& Morisky, D. E. (1998). Applying the theory of reasoned action to condom use among sex workers. Social Behavior and Personality, 26(4), 317-328.

Taiwan Centers for Disease Control, Department of Health, Executive Yuan (2005). CDC annual report 2005. Taipei: Centers for Disease Control.

Taiwan Centers for Disease Control, Department of Health, Executive Yuan (2007). CDC annual report 2007. Taipei: Centers for Disease Control. 
Taiwan Centers for Disease Control, Department of Health, Executive Yuan (2008). CDC annual report 2008. Taipei: Centers for Disease Control.

Taiwan Centers for Disease Control, Department of Health, Executive Yuan (2009). HIV/AIDS statistics. Taipei: Centers for Disease Control.

Taiwan Department of Health, Executive Yuan (2005). Harm reduction program project. Taipei: DOH.

Taiwan Department of Health, Executive Yuan (2006). The fourth national strategic plan (2007-2011). Taipei: DOH.

Twu, S. J., Huang, Y. F., Lai, A. C., Ming, N., \& Su, I. (2004). Update and projection on HIV/AIDS in Taiwan. AIDS Education and Prevention, 16(Suppl A), 53-63.

UNAIDS (2008). 2008 Report on the global AIDS epidemic. Geneva: UNAIDS.

UNESCO (1997). International Standard Classification of Education (ISCED) 1997. Paris: UNESCO.

UNESCO (2006). Non-formal education, Chap. 12. In Guidebook for planning education in emergencies and reconstruction (pp. 1-16). Paris: International Institute for Educational Planning.

United States Agency for International Development (2008). Philippines. HIV/AIDS health profile. Pasay City, Philippines: United States Government Printing Office.

Urada, L., Thomas, T., Morisky, D., \& Malow, R. (2008). An expanded community-based HIV prevention programme in the Philippines. In B. Stanton, J. Galbraith, \& L. Kaljee (Eds.), The uncharted path from clinic-based to community-based research (pp. 104-122). New York: Nova Science Publishers.

Vermund, S. H., Allen, K. L., \& Karim, Q. A. (2009). HIV-prevention science at a crossroads: Advances in reducing sexual risk. Current Opinion in HIV and AIDS, 4(4), 266-273.

Wi, T., Ramos, E. R., Steen, R., Esguerra, T. A., Roces, M. C. R., Lim-Quizon, M. C., et al. (2006). STI declines among sex workers and clients following outreach, one time presumptive treatment, and regular screening of sex workers in the Philippines. Sexually Transmitted Infections, 82(5), 386-391.

\section{Author Biographies}

Donald E. Morisky (United States of America), Sc.D., Sc.M., M.S.P.H. is Professor and Director of the Doctoral Training Program in the Social and Behavioral Determinants of HIV/AIDS Prevention at the University of California at Los Angeles, School of Public Health, Department of Community Health Sciences, 650 Charles E. Young Drive South, Box 951772, 26-070 CHS, Los Angeles, CA 90095-1772. Morisky's research addresses the social and behavioral determinants of infectious and chronic diseases management and the role of provider/patient communication and family-member involvement in improving adherence to medical recommendations. For over 30 years he has conducted research in Asia, addressing global health issues such as maternal and child health, family planning, and the prevention and control of infectious diseases (e.g., tuberculosis and HIV/AIDS). In 2006, he was awarded the prestigious Elizabeth Fries Prize for substantial contribution to advancing the field of health education/health promotion through research, programme development, and programme delivery. He has served as a Distinguished Visiting Professor at the Taipei Medical University and the National Yang-Ming University, Taipei, Taiwan.

Shu-Yu Lyu (Taiwan), Ph.D., M.P.H. is an Associate Professor in the School of Public Health and Director of the Indigenous Health Research Center, Taipei Medical University. She received her M.P.H. from the University of North Carolina at Chapel Hill, and her Ph.D. in the field of community health sciences from the School of Public Health at the University of California, Los Angeles. After earning her master's degree, she worked in the Department of Health in Taiwan's Executive Yuan for 7 years. Since 1997, she has conducted surveys on HIV/AIDS knowledge and risk behaviors among injection drug users. She also joined the research team of the AIDS Prevention and Research Center at National Yang-Ming University, Taipei, Taiwan.

Lianne A. Urada (United States of America), M.S.W., L.C.S.W. is a doctoral candidate at the University of California, Los Angeles, Department of Social Welfare, School of Public Affairs, 3250 Public Affairs Building, Los Angeles, CA 90095. She received her master's degree in social welfare at UCLA. For the past 8 years she has counseled people living with HIV/AIDS and conducted community-based HIV prevention intervention research with female entertainers and their establishment managers in the Metro Manila area, the Philippines. 